\title{
The 28th International Mammalian Genome Conference-meeting report
}

\author{
William T. Barrington ${ }^{1} \cdot$ Andrew P. Morgan $^{2} \cdot$ Linda D. Siracusa ${ }^{3}$
}

Received: 11 March 2015/Accepted: 8 April 2015/Published online: 22 April 2015

(C) Springer Science+Business Media New York 2015

\section{Introduction}

The 28th International Mammalian Genome Conference (IMGC) was held October 26-29th, 2014 in scenic Bar Harbor, Maine. In addition to being the home of The Jackson Laboratory, Mount Desert Island is a popular summer vacation destination. More than 200 attendees of the conference enjoyed the last few days of the tourist season as the autumn leaves fell and the local residents prepared for winter. Darla Miller and Dasha Li Kappe organized the meeting, with the help of local organizers Ron Korstanje, Karen Svenson, Erin McDevitt, and Nancy Place. Scientists presented cutting-edge research in the fields of mammalian genetics and genomics that highlighted the importance of mammalian models for human genetics and disease research. The plenary presentations demonstrated the broad applicability of mammalian models to study a range of topics from gene evolution to rare human diseases. Meanwhile, the Verne Chapman lecture provided a historical account of mouse genetics research and encouraged a new, automated approach to forward genetics. Bioinformatics and Systems Genetics Workshops gave participants hands-

Linda D. Siracusa

Linda.Siracusa@jefferson.edu

1 Department of Biological Sciences, North Carolina State University, 3510 Thomas Hall, Raleigh, NC 27695, USA

2 Department of Genetics, Carolina Center for Genome Sciences, University of North Carolina at Chapel Hill, Chapel Hill, NC 27599, USA

3 Department of Microbiology and Immunology, Thomas Jefferson University, 233 South 10th Street, Philadelphia, PA 19107, USA on opportunities to become familiar with genetic and genomic tools. A student satellite symposium afforded budding scientists the chance to share their work and two poster sessions encouraged interaction among researchers. The meeting program and abstracts are available online at www.imgs.org/Archive/abstracts/2014Abstracts/IMGS2014 Program.pdfwww.imgs.org. Online resources presented at the meeting are listed in Table 1.

\section{Bioinformatics workshops}

Several workshops provided conference attendees with opportunities for hands-on guided tours of publicly available informatics resources relevant to IMGS members.

The pre-conference Bioinformatics Workshop offered three mini-sessions: (1) a guide to genome annotations produced by the GENCODE consortium, and differences between annotation sets provided by popular databases (Laurens Wilming, Wellcome Trust Sanger Institute); (2) an overview of the International Knockout Mouse Consortium's pipeline and progress (Mark Thomas, Wellcome Trust Sanger Institute); and (3) a tour of the International Mouse Phenotyping Consortium's database of mutant mouse phenotypes (www.mousephenotype.org). An online link to these workshop powerpoint presentations can be found under the "History" tab on the IMGS home page (www.imgs.org).

The System Genetics Workshops, led by Dan Gatti (The Jackson Laboratory), Marty Ferris (University of North Carolina at Chapel Hill), Gary Churchill (The Jackson Laboratory) along with Andrew Morgan and Fernando Pardo-Manuel de Villena (University of North Carolina at Chapel Hill) featured talks on the design and status of two important multiparental genetic reference populations, the Collaborative Cross (CC) and the Diversity Outbred (DO) 
Table 1 Databases, resources, and tools

\begin{tabular}{|c|c|c|}
\hline Resource & Acronym & URL address \\
\hline Collaborative Cross status page and tools & $\mathrm{CC}$ & www.csbio.unc.edu/CCstatus/index.py \\
\hline CrePortal Resource for Conditional Mutagenesis in the Mouse & & www.creportal.org \\
\hline Diversity Outbred stock and datasets & DO & www.do.jax.org \\
\hline Functional Annotation of the Mammalian Genome & FANTOM5 & www.fantom.gsc.riken.jp/5/ \\
\hline Gene eXpression Database & GXD & www.informatics.jax.org/expression.shtml \\
\hline Human-Mouse: Disease Connection & HMDC & www.diseasemodel.org \\
\hline International Mouse Phenotyping Consortium & IMPC & www.mousephenotype.org \\
\hline Infrafrontier Mouse Disease Models & & www.infrafrontier.eu \\
\hline MouseBook & & www.mousebook.org \\
\hline Mouse Encyclopedia of DNA Elements & ENCODE & www.mouseencode.org/ \\
\hline Mouse Genome Informatics & MGI & www.informatics.jax.org \\
\hline Mouse Phenome Database & MPD & www.phenome.jax.org \\
\hline Mouse Tumor Biology Database & MTB & www.tumor.informatics.jax.org \\
\hline NHGRI-EBI Catalog of Published GWAS & & www.genome.gov/gwastudies/, www.ebi.ac.uk/gwas/ \\
\hline Rat Genome Database & RGD & www.rgd.mcw.edu/ \\
\hline Sanger Mouse Genomes Project & MGP & www.sanger.ac.uk/resources/mouse/genomes/ \\
\hline Sanger Mouse Resources Portal & & www.sanger.ac.uk/mouseportal/ \\
\hline \multicolumn{3}{|l|}{ Analysis tools } \\
\hline Combined Analysis of Pleiotropy and Epistasis Package & CAPE & www.cran.r-project.org/web/packages/cape \\
\hline $\begin{array}{l}\text { DOQTL: a package for genetic mapping } \\
\text { in the Diversity Outbred stock }\end{array}$ & DOQTL & $\begin{array}{l}\text { www.bioconductor.org/packages/release/bioc/html/ } \\
\text { DOQTL.html }\end{array}$ \\
\hline EM estimation of allele-specific expression & EMASE & www.github.com/jax-cgd/emase \\
\hline GeneWeaver System & & www.geneweaver.org \\
\hline MouseMine: integrated mouse data & & www.mousemine.org/mousemine/begin.do \\
\hline Multi-String Burrows Wheeler Transform Utility Suite & MSBWT & www.pypi.python.org/pypi/msbwt \\
\hline \multicolumn{3}{|l|}{ Multispecies genome browsers } \\
\hline Ensembl Genome Browser & ENSEMBL & www.ensembl.org \\
\hline National Center for Biotechnology Information & NCBI & www.ncbi.nlm.nih.gov/ \\
\hline UCSC Genome Bioinformatics & & www.genome.ucsc.edu/ \\
\hline \multicolumn{3}{|l|}{ Nomenclature guidelines } \\
\hline Human Gene Nomenclature Committee & HGNC & www.genenames.org/ \\
\hline Mouse Nomenclature Home Page & & www.informatics.jax.org/mgihome/nomen/ \\
\hline Rat Nomenclature Guidelines & & www.rgd.mcw.edu/nomen/nomen.shtml \\
\hline \multicolumn{3}{|l|}{ Repositories } \\
\hline European Mouse Mutant Archive & EMMA & www.emmanet.org, https://www.infrafrontier.eu \\
\hline European Mouse Mutant Cell Repository & EuMMCR & www.eummcr.org \\
\hline International Mouse Strain Resource & IMSR & www.findmice.org \\
\hline JAX Mice Database & JAX & www.jaxmice.jax.org/query \\
\hline NIH Knockout Mouse Project & KOMP & www.nih.gov/science/models/mouse/knockout/ \\
\hline NCI at Frederick Mouse Repository & & www.mouse.ncifcrf.gov \\
\hline The Mouse Mutant Resource & MMR & www.mousemutant.jax.org \\
\hline UC Davis KOMP repository & KOMP & www.komp.org \\
\hline
\end{tabular}

mice. Didactic sessions were supplemented with smallgroup discussions on rational experimental designs using these populations and available online tools for analyses
(www.csbio.unc.edu/CCstatus/index.py) were described by Leonard McMillan, Chen-Ping Fu, and Chia-yu Kao (University of North Carolina at Chapel Hill). 
This year's Mouse Genome Informatics (MGI) Workshops (www.informatics.jax.org) were led by Joanne Berghout and David Shaw (The Jackson Laboratory). The hands-on workshops included seminar-style demonstrations followed by the opportunity to navigate MGI using self-guided exercises. Participants were instructed on how to locate biological information by performing a variety of searches, and were also introduced to new tools such as the Human-Mouse: Disease Connection portal (www.informatics.jax.org/humanDisease. shtml), the Recombinase (Cre) Activity portal (www.infor matics.jax.org/recombinase.shtml), and the MouseMine computational access platform (www.mousemine.org/mou semine/begin.do).

In celebration of the 25th birthday of the MGI database, Janan Eppig (The Jackson Laboratory; O-30) tracked the history of the MGI from a pre-web version distributed on floppy disks to the MGI website (www.informatics.jax.org) that we know today. Janan emphasized the continued commitment of MGI to provide integrated genetic, genomic, and biological data for mouse and to provide increased access to translational data views to support discovery and hypothesis building for studies of human disease. Janan also recognized the contributions of many individuals who worked to develop MGI over the years and described future plans as MGI evolves to meet the growing needs of the scientific community.

\section{Trainee conference}

As in past years, there was a strong emphasis placed on mentoring young scientists at the IMGC. The IMGS awarded 31 travel scholarships to students and postdoctoral fellows; these trainee scholarships were sponsored by Mouse News Letter, Ltd. and IMGS, Inc. Young scientists had opportunities to share their research and interact with other scientists in their field. The mentor lunch afforded students and postdoctoral fellows the opportunity to meet and seek the advice of experienced scientists.

Following the Bioinformatics Workshop, the student satellite symposium was held in The Jackson Laboratory's auditorium. Sixteen trainees were selected to give oral presentations on their work. These exceptional talks covered a wide range of topics from somatic cell reprogramming to the genetic basis of opossum craniofacial morphology. Judges scored the talks, and four students (Sarah Leist, Andrew Morgan, Clare Smith, and Kart Tomberg; Table 2) were awarded the Lorraine Flaherty Prize, which gave them an opportunity to present their talk at the main conference.

Several trainees presented research using mouse models for human health and disease. Dean Ihemesie (Thomas Jefferson University; SO-06) described his work investigating the strain-dependent differences in susceptibility to colon cancer in the $A p c^{M i n}$ mouse model using Ingenuity Pathway
Analysis. Nithya Kartha (Cornell University; SO-07) is investigating the sporadic initiating events that drive mammary carcinogenesis in the $\mathrm{C} 3 \mathrm{H}-$ Chaos 3 mouse. Of particular interest is Aridla, a tumor suppressor gene, which is frequently deleted in $\mathrm{C} 3 \mathrm{H}-$ Chaos3 mammary tumors and mutated in other tumors. Leslie Roteta (Vanderbilt University; SO-13) presented research which demonstrated that high-density lipoprotein (HDL)-mediated miRNA intracellular communication is suppressed in type 2 diabetes and restored by diabetic drug treatments. HDL-miRNA transfer may represent a novel form of endocrine-like communication in type 2 diabetes. Natalia Gonzales (University of Chicago; SO-05) presented results of a genome-wide association study of conditioned place preference for methamphetamine in an LG/J x SM/J advanced intercross line. William Barrington (North Carolina State University; SO-02) is using four inbred mouse strains to investigate how genetic background impacts the physiological response to diet. Michelle Simon (MRC Harwell; SO-14) explained how the Harwell Ageing Screen uses ENU-mutagenized mice to identify effects of single nucleotide variants on age-related phenotypes. All predicted SNVs and numerous aging phenotypes are disseminated via MouseBook (www.mousebook.org).

Several talks centered on pathogen infection. Sarah Leist (Helmholtz Centre for Infection Research; SO-08) discussed her analysis of host response to Influenza A in $8 \mathrm{CC}$ founder strains and $4 \mathrm{CC}$ lines. Clare Smith (University of Massachusetts Medical School; SO-15) reported on her work mapping host-pathogen genetic interactions in tuberculosis infection for BXD RI and CC panels. Her work identified that the disease spectrum of the $\mathrm{CC}$ lines exceeded the disease spectrum of the $\mathrm{CC}$ progenitor strains as well as other previously characterized inbred strains. QTL analysis is underway to identify polymorphisms associated with alterations in disease and bacterial mutant fitness.

Two presenters discussed the topics of genome evolution and variation. Andrew Morgan (University of North Carolina at Chapel Hill; SO-09) presented the natural history of $R 2 d 2$, the responder in a recently-described meiotic drive system, and discussed the evolutionary basis for the maintenance of high levels of polymorphism at the locus. Arthur Porto (Washington University in St. Louis; SO-11) shared his research on the genetic basis of morphological variation in the opossum skull. Several QTL contributing to individual differences in craniofacial structure were identified in an F2 intercross.

Some students discussed new computational tools for QTL mapping and RNA-Seq analysis. Chen-Ping Fu (University of North Carolina at Chapel Hill; SO-03) shared her work developing a novel approach to QTL mapping that directly uses microarray marker intensities. The approach compared favorably to R/qtl and successfully mapped the binary albino trait to the Tyr gene in a backcross. Narayanan Raghupathy (The Jackson Laboratory; SO-12) described the use of a new 
Table 2 Awardees

\begin{tabular}{|c|c|c|c|}
\hline Awardee & Institute & Title & Award/sponsor \\
\hline Clare Smith & $\begin{array}{l}\text { University of } \\
\text { Massachusetts } \\
\text { Medical School, } \\
\text { USA }\end{array}$ & $\begin{array}{l}\text { Mapping host-pathogen genetic interactions to } \\
\text { understand tuberculosis pathogenesis }\end{array}$ & $\begin{array}{l}\text { Verne Chapman Young Scientist Award } \\
\text { (\$500) and Lorraine Flaherty Memorial } \\
\text { Award/IMGS }\end{array}$ \\
\hline $\begin{array}{r}\text { Melissa } \\
\text { Harris }\end{array}$ & $\begin{array}{l}\text { National Human } \\
\text { Genome Research } \\
\text { Institute, USA }\end{array}$ & $\begin{array}{l}\text { Hair graying as a model to investigate the genetics of } \\
\text { stem cell maintenance }\end{array}$ & $\begin{array}{l}\text { OOP_-subscription to Genetics and } \$ 300 / \\
\text { IMGS }\end{array}$ \\
\hline Sarah Leist & $\begin{array}{l}\text { Helmholtz Centre for } \\
\text { Infection Research, } \\
\text { Germany }\end{array}$ & $\begin{array}{l}\text { Analysis of the host response to influenza A virus } \\
\text { infection in the Collaborative Cross founder strain }\end{array}$ & $\begin{array}{l}\text { OOP_subscription to Mammalian Genome, } \\
1 \text { year IMGS membership, and Lorraine } \\
\text { Flaherty Memorial Award/IMGS }\end{array}$ \\
\hline $\begin{array}{l}\text { Andrew } \\
\text { Morgan }\end{array}$ & $\begin{array}{l}\text { University of North } \\
\text { Carolina, USA }\end{array}$ & $\begin{array}{l}\text { Genome evolution by duplication and differential } \\
\text { loss in Mus musculus }\end{array}$ & $\begin{array}{l}\text { OOP_-subscription to Genomics and Lorraine } \\
\text { Flaherty Memorial Award/IMGS }\end{array}$ \\
\hline $\begin{array}{l}\text { Kart } \\
\text { Tomberg }\end{array}$ & $\begin{array}{l}\text { University of } \\
\text { Michigan, USA }\end{array}$ & $\begin{array}{l}\text { Spontaneous } 8 \text { bp deletion in Nbeal2 recapitulates } \\
\text { the grey platelet syndrome in mice }\end{array}$ & $\begin{array}{l}\text { OOP-Genetics of Mouse from Springer and } \\
\text { Lorraine Flaherty Memorial Award/IMGS }\end{array}$ \\
\hline $\begin{array}{l}\text { Dean } \\
\text { Ihemesie }\end{array}$ & $\begin{array}{l}\text { Thomas Jefferson } \\
\text { University, USA }\end{array}$ & $\begin{array}{l}\text { Network detection for susceptibility genes } \\
\text { predisposing to intestinal and colon cancers }\end{array}$ & $\begin{array}{l}\text { Outstanding Nomenclature on a Research } \\
\text { Poster Award/ICSGNM }\end{array}$ \\
\hline $\begin{array}{l}\text { Nicole } \\
\text { Savignac }\end{array}$ & $\begin{array}{r}\text { Georgia Institute of } \\
\text { Technology, USA }\end{array}$ & $\begin{array}{l}\text { Using human GWAS to mine phenotypic variation in } \\
\text { the Diversity Outbred mouse population }\end{array}$ & $\begin{array}{l}\text { OOP_-subscription to Mammalian Genome } \\
\text { and } 1 \text { year IMGS membership }\end{array}$ \\
\hline $\begin{array}{l}\text { Tania } \\
\text { Arguello }\end{array}$ & $\begin{array}{l}\text { University of Miami, } \\
\text { USA }\end{array}$ & $\begin{array}{l}\text { A } \mathrm{T} \text { to } \mathrm{C} \text { mutation in the conserved spacer region in } \\
\text { one of the loxP sites inhibits the cre recombinase } \\
\text { activity in vivo but not ex vivo }\end{array}$ & $\begin{array}{l}\text { ORP-Manipulating the Mouse Embryo from } \\
\text { genesis }\end{array}$ \\
\hline Morag Lewis & $\begin{array}{l}\text { King's College } \\
\text { London, UK }\end{array}$ & $\begin{array}{l}\text { Collateral damage: Identification and characterisation } \\
\text { of spontaneous mutations from a targeted knockout } \\
\text { programme }\end{array}$ & ORP-Mouse Phenotypes from genesis \\
\hline Leslie Roteta & $\begin{array}{l}\text { Vanderbilt University, } \\
\text { USA }\end{array}$ & $\begin{array}{l}\text { High-density lipoproteins mediate microRNA } \\
\text { intercellular communication in type } 2 \text { diabetes }\end{array}$ & ORP-Mouse Phenotypes from genesis \\
\hline $\begin{array}{l}\text { Narayanan } \\
\text { Raghupathy }\end{array}$ & $\begin{array}{l}\text { The Jackson } \\
\text { Laboratory, USA }\end{array}$ & $\begin{array}{l}\text { Quantifying allele-specific alternative splicing in } \\
\text { personalized genomes using EM algorithm }\end{array}$ & $\begin{array}{l}\text { ORP-Manipulating the Mouse Embryo from } \\
\text { genesis }\end{array}$ \\
\hline $\begin{array}{l}\text { Natalia } \\
\text { Gonzales }\end{array}$ & $\begin{array}{l}\text { University of Chicago, } \\
\text { USA }\end{array}$ & $\begin{array}{l}\text { Genome-wide association study of behavior in an } \\
\text { advanced intercross line of mice }\end{array}$ & ORP-Mouse Phenotypes from genesis \\
\hline Joy Gary & $\begin{array}{l}\text { Michigan State } \\
\text { University/National } \\
\text { Cancer Institute, } \\
\text { USA }\end{array}$ & $\begin{array}{l}\text { Genetic and pharmacologic inhibition of MTOR } \\
\text { delays thymic lymphoma formation and decreases } \\
\text { CDK6 levels }\end{array}$ & $\begin{array}{l}\mathrm{OOP} \text { - complimentary registration to AACR } \\
\text { meeting of choice/AACR }\end{array}$ \\
\hline $\begin{array}{l}\text { Nithiya } \\
\text { Kartha }\end{array}$ & $\begin{array}{l}\text { Cornell University, } \\
\text { USA }\end{array}$ & $\begin{array}{l}\text { Identifying key driver events in the } \mathrm{C} 3 \mathrm{H}-\text { Chaos } 3 \\
\text { mouse model for breast cancer }\end{array}$ & $\begin{array}{l}\mathrm{ORP} \text { - complimentary registration to AACR } \\
\text { meeting of choice/AACR }\end{array}$ \\
\hline $\begin{array}{l}\text { Christopher } \\
\text { Baker }\end{array}$ & $\begin{array}{l}\text { The Jackson } \\
\text { Laboratory, USA }\end{array}$ & $\begin{array}{l}P R D M 9 \text { drives the evolution of recombination } \\
\text { hotspots }\end{array}$ & OOP-subscription to Genome Research \\
\hline $\begin{array}{l}\text { Annie } \\
\text { Weisner }\end{array}$ & $\begin{array}{l}\text { University of Illinois } \\
\text { at Urbana- } \\
\text { Champaign, USA }\end{array}$ & $\begin{array}{l}\text { A reciprocal translocation disrupts } A u t s 2 \text { gene } \\
\text { expression in a novel mutant strain }\end{array}$ & OOP-subscription to Genetics Research \\
\hline
\end{tabular}

IMGS International Mammalian Genome Society (www.imgs.org/), OOP outstanding oral presentation, ICSGNM International Committee on Standardized Genetic Nomenclature for Mice (www.informatics.jax.org/mgihome/nomen/), ORP outstanding research poster, AACR American Association for Cancer Research (www.aacr.org/Pages/Home.aspx)

computational tool, EMASE, which uses an EM algorithm to quantify allele-specific alternative splicing in RNA-Seq analyses and demonstrated the utility of the approach in several applications.

Tiffany Garbutt (North Carolina State University; SO-04) presented her work reprogramming fibroblast cells from CC founder strains to induced pluripotent stem cells. Two strains, NOD and WSB, were found to be non-permissive. Studies are underway to identify influential factors on pluripotency. Danitza Nebor (The Jackson Laboratory; SO-
10) described her work using DO mice to identify novel genetic regulators of $\beta$-like globin switching. Kart Tomberg (University of Michigan; SO-16) presented her work on a spontaneous 8 bp deletion in the 129S1 strain, which recapitulates the gray platelet syndrome in mice. Tania Arguello (University of Miami; SO-01) demonstrated the specificity required of the Cre/loxP system in vivo showing that a single $\mathrm{T}$ to $\mathrm{C}$ mutation in the loxP site completely inhibits the recombination reaction in two conditional mouse models, but did not inhibit recombination in cell culture. 
In addition to the student satellite symposium, two poster sessions allowed 89 presenters the opportunity to share and discuss their work with attendees of the main conference. The winners of special awards for outstanding presentations in several categories are listed in Table 2.

\section{Comparative genomics, population genetics, and evolution}

The IMGC brings together a diverse group of researchers, many of whom are interested in using the mouse as a model for basic biology and/or human disease, but also many who use the mouse to study genome evolution and populationlevel genome dynamics. This year's session on comparative genomics and evolution was highlighted by several talks on chromosome segregation and meiosis. Fernando PardoManuel de Villena (University of North Carolina at Chapel Hill; O-01) opened the session with a description of his laboratory's characterization (with important contributions from many in the audience) of a novel meiotic drive system, in which a locus controls its own segregation in cis. Chris Baker (The Jackson Laboratory; O-02) presented work on the co-evolution of the Prdm9 protein, which marks recombination hotspots, and its recognition sequence, shedding light on the so-called "hotspot paradox." Insights into the relationship between sequence divergence defects in chromosome synapsis, and inter-subspecific sterility were traced to incompatibility between $\operatorname{Prdm} 9$ and Hstx2 alleles by Jiri Forejt (Academy of Sciences of the Czech Republic; O-05).

Two complementary talks from Dan Gatti (The Jackson Laboratory; O-04) and David Aylor (North Carolina State University; O-06) integrated newly available annotation data from Sanger Mouse Genomes Project and the Mouse ENCODE Project with gene expression and DNase I hypersensitivity data to identify causal variants influencing expression of nearby genes.

Finally, Lisa DiCarlo (Florida State University College of Medicine; O-03) gave a thought-provoking talk on the effect of estrous cycle on gene expression in brain in female mice. She showed that expression variation between brain regions is greater than between stages of the estrous cycle, an observation that has important implications for experimental design in neuroscience.

\section{Human disease models}

The use of mouse models for human disease research is always an important topic at the IMGC. This year, a number of speakers presented their work on neurodevelopment and neurological disorders. Annie Weisner (University of Illinois; O-17) presented her work on Auts2, a recently discovered gene implicated in neurodevelopment disorders. Her group has developed a mutant mouse model to study the function of Auts2 and test the hypothesis that Auts2 expression is necessary for normal neurodevelopment on a cellular and systemic level. Dawn Watkins-Chow (National Human Genome Research Institute; O-40) presented her work identifying genetic modifiers of Niemann-Pick disease, type C (NPC), and a fatal neurodegenerative disorder. Her group has used a high-throughput siRNA-based screen in addition to a mouse model of NPC to identify candidate modifier genes. Rob Houtmeyers (Katholieke Universiteit Leuven; O-07) presented his work identifying the molecular basis for Zic2-associated holoprosencephaly.

Two speakers discussed collaborative efforts aimed at better understanding neurological disorders. Darren Logan (Wellcome Trust Sanger Institute; O-27) described phenotypic analyses of mouse models derived from the Windows of Hope and Deciphering Development Disorders projects, two consortia which are studying the causes of inherited conditions in US Anabaptist populations and the genetic basis of neurodevelopmental disorders in UK children, respectively. Binnaz Yalcin (University of Lausanne; O-19) discussed a collaborative effort with the Sanger Mouse Genetics Project to systematically study the neuroanatomy of the MGP/IMPC knockout mouse strains using a panel of standardized parameters. Thus far, brain defects in 425 knockout mouse mutants have been assessed yielding the identification of 20 known intellectual disability genes and 21 other genes that caused modification of brain structures upon disruption.

Rolf Stottmann (Cincinnati Children's Hospital Medical Center; O-39) discussed his research on the role of primary cilia in neural ciliopathic disease. His group is using a series of Cre transgenic mouse lines to identify the spatiotemporal role of genes involved in forebrain ciliary function. Casey McKenzie (Sanford Research; O-35) presented results of a study, which identified an essential role for cilia and flagella associated protein $54\left(\mathrm{CFAP}_{54}\right)$ in assembly of mammalian cilia and flagella. This work established a new mouse model of primary ciliary dyskinesia (PCD), a syndrome characterized by hydrocephalus and susceptibility to respiratory infections in childhood and infertility in adulthood.

Several researchers' talks focused on cancer etiology and tumorigenesis. Rachel Lynch (Texas A\&M University; O-13) shared her work comparing tumorigenesis in several transgenic mouse models of metastatic colorectal cancer. Denise Lanza (Baylor College of Medicine; O-14) discussed her investigation into the role of cyclin D1 in testicular germ cell tumorigenesis using a 129 inbred mouse model. Using genetic and pharmacologic inhibition of MTOR, Joy Gary (Michigan State University/National Cancer Institute; O-16) demonstrated delays in thymic 
lymphoma formation accompanied by decreases in CDK6. Her research identified simultaneous targeting of the MTOR pathway and CDK6 as a promising treatment for T cell acute lymphoblastic leukemias. In the Advances in Genome Manipulation session, Viive Howell (University of Sydney; O-53) described a model for ovarian cancer using mice that contained a mutant $\operatorname{Trp} 53$ allele or a floxed Brcal allele, with adenoviral Cre delivered by direct injection into the ovary to activate Sleeping Beauty mutagenesis. Interestingly, only mice that contained a mutant Trp53 allele developed ovarian tumors. This study identified potential driver genes of ovarian cancer, including kinases and tumor suppressor genes.

Other investigators focused on using mice to model metabolic phenotypes and determine their genetic basis. Brian Bennett (University of North Carolina at Chapel Hill; O-29) discussed his work on trimethylamine N-oxide (TMAO) and betaine and their effect on atherosclerosis. Bennett's group is working to define the genetic and dietary factors that regulate TMAO using the Hybrid Mouse Diversity Panel and the DO population. Nicole Savignac (Georgia Institute of Technology; O-12) also used the DO population and integrated findings from human GWAS studies to analyze metabolic traits present in the DO population. Meanwhile, Tim Wiltshire (University of North Carolina at Chapel Hill; O-28) is using CC mice to evaluate liver response to tolvaptan, a promising candidate drug for the treatment of autosomal dominant polycystic kidney disease (ADPKD) that has not received FDA approval due, in part, to idiosyncratic drug-induced liver injury (DILI). Three sensitive CC strains have been identified and are under further investigation. Gail Herman (Nationwide Childrens Hospital Research Institute; O-10) has investigated cholesterol synthesis deficiencies due to inactivation of the cholesterologenic enzyme, NSDHL, using a conditional targeted allele that enables evaluation of different development stages and cell types.

Hisashi Oishi's (University of Tsubuka; O-37) group created a transgenic mouse that has a $200-\mathrm{kbp}$ fragment with an insulin I gene that drives luciferase expression. This new model allows for noninvasive imaging of islet $\beta$ cells under normal and pathological conditions. Cathleen Lutz (The Jackson Laboratory; O-11) reported on a new mouse model of Spinal Muscular Atrophy (SMA), which has mild disease related and comorbidity phenotypes. Systemic administration of survival of motor neuron (SMN)-inducing compounds at two different timepoints was able to ameliorate SMA-like symptoms and comorbidity.

Sally Cross (MRC Institute of Genetics and Molecular Medicine; O-09) has used ENU mutagenesis to identify a gain of function mutation in Tmem98 which causes Bochdalek congenital diaphragmatic hernia, a malformation present in 1 in 2500 live human births for which there is no syndromic mouse model. Elisabeth Lodder (Academic Medical Center, Amsterdam; O-15) presented new loci and candidate genes from a QTL mapping study of electrocardiographic parameters and cardiac gene expression in BXD RI strains. Esther Zurita (National Centre for Biotechnology, Madrid; O-36) used a variety of gene mapping techniques and next-generation sequencing to identify the mutations in the Gnat2 gene, which are present in 30-40\% of commercial stocks of common outbred albino mice. The same mutation has been shown to produce achromatopsia, a disease causing color blindness. The results have implications for the use of albino outbred mice for research involving retina, vision, or behavioral studies. Daniel Prows (Cincinnati Childrens Hospital Medical Center; O-38) is using a mouse model to identify the genetic basis of mortality risk after sustaining an acute lung injury. Genetic analyses of backcross and F2 cohorts of sensitive (C57BL/6J) and resistant (129X1/SvJ) strains has yielded the candidate QTLs Shali1 and Shali2.

In the Advances in Genome Manipulation session, Richard Woychik (National Institute of Environmental Health Sciences; O-56) described intriguing studies of intracisternal A-Particle (IAP) elements and their role in cocaine addiction, using the mouse as a model for human disease. His studies showed that the expression profile of chimeric IAP-gene transcripts in the nucleus accumbens of cocaine-treated mice is significantly different than in control mice. Karen Svenson (The Jackson Laboratory; O-18) gave a brief historical account on the establishment of the housing density recommendations in The Guide for the Care and Use of Laboratory Animals and presented new studies on how housing density affects mouse growth, behavior, and physiology in inbred and hybrid mouse strains. These studies demonstrate that mice can be housed at up to twice the density recommended with no adverse effects on physiology and well-being.

\section{Stem cells and development/aging and adult-onset disease modeling}

The study of stem cells and aging is becoming a more central theme to understanding self-renewal and differentiation. This year's presentations covered a broad array of topics, from melanocytes and aging to the study of novel genes impacting neurodegenerative disease. Melissa Harris (National Human Genome Research Institute; O-21) gave an elegant presentation highlighting the use of the mouse to study hair graying as a model for stem cell maintenance. Using a Sox10 mutant sensitized to developing gray hairs, she demonstrated that inbred strain background impacts the differentiation of melanocyte stem cells and that identification of modifying genes could be useful to uncover gene 
networks involved in aging. Temesgen Fufa (National Human Genome Research Institute; O-26) described studies of the cistrome of Sox10 in proliferating melanocytes, using a combination of ChIP-Seq and gene expression arrays. He showed that the functional roles of Sox10activated targets are distinct from the functional roles of Sox10-repressed targets, thus expanding the impact of Sox10 in the melanocyte lineage. In the Advances in Genome Manipulation session, Michelle Southard-Smith (Vanderbilt University; O-55) described the generation of a COnditional INducible dominant negative allele of Sox10 (termed Sox10-COIN) which uses a fluorescent tag to label neural crest derivatives when the Sox10 isoform has been activated by Cre. This disruption of Sox 10 in distinct neural crest lineages now provides a means to investigate developmental processes and progenitor cell function in various neuropathies.

Candice Byers (The Jackson Laboratory; O-22) showed how whole-genome sequencing can be used to pinpoint the gene responsible for a monogenic phenotype, namely the spontaneous jagged-tail $(\mathrm{jgl})$ mutation. Homozygosity for $j g l$ results in disrupted spermatogenesis as well as depletion of germ cells in both males and females; the source of the depletion was traced back to gestation. Kendra Williams (National Human Genome Research Institute; O-23) described the use of a transgenic TRAMP mouse model of neuroendocrine prostate cancer. These investigators combined results from a mouse intercross with gene expression data from human tumors and GWAS studies for prostate cancer susceptibility to identify candidate genes influencing the aggressive form of this disease. Teresa Gunn (McLaughlin Research Institute; O-24) spoke about her work with the E3 ubiquitin ligase mahogunin ring finger 1 (Mgrnl) gene, which when mutated results in a widespread and progressive spongiform neurodegeneration; in an elegant study, she showed that loss of the Mgrn1 protein disrupts mitochondrial function both in vitro as well as in vivo, thus implicating a role for Mgrnl in mitochondrial homeostasis. Heena Lad (MRC Harwell; O-25) discussed ENU mutagenesis and identification of a novel phenotype for the Whirlin (Whrn) gene, a gene associated with Usher Syndrome Type II deafness in humans. Her group found a specific mutation in the Whrn gene that does not cause overt deafness, but does cause a novel head bob phenotype, thus expanding the functional roles of the Whrn gene.

\section{Large-scale resources}

The IMGC remains an important venue for coordinators of large-scale research resources to provide updates to the mammalian genetics community. Comprehensive phenotypic characterization of clinical phenotypes in the $\mathrm{CC}$ founder strains was presented by Klaus Schughart (Helmholtz Centre for Infection Research; O-48) and Birgit Rathkolb (Ludwig-Maximilians-Univertitaet; O-50). Stephen Murray (The Jackson Laboratory; O-52) described the use of embryo-level phenotyping to recover information about early-acting lethal mutations in the Knockout Mouse Phenotyping Program (KOMP2). The work of Laura Reinholdt and Heather Fairfield (The Jackson Laboratory; O-46, O-49) provided reverse genetics to complement the forward genetics of KOMP2. They combined whole-exome sequencing and gene expression profiling by RNA-Seq with extensive pedigree detective work to identify causal variants underlying Mendelian disorders in 91 historical mutant stocks maintained at The Jackson Laboratory.

Analysis and informatics tools constitute increasingly important community resources as biologists shift in the direction of "big data." Thomas Keane (Wellcome Trust Sanger Institute; O-47) announced the release of wholegenome sequence, variant calls, and de novo assemblies for 11 additional mouse strains to complement the 17 strains already available via the Sanger Mouse Genomes Project, and previewed upcoming strain-specific gene predictions. Matthew Holt (University of North Carolina at Chapel Hill; O-32) presented an exciting new tool for compressing and indexing next-generation sequencing data which allow fast searches across unaligned sequence reads even in very large datasets. Kwangbom Choi (The Jackson Laboratory; O-46) presented a new statistical method for simultaneously estimating isoform-, strain- and allele-specific gene expression by RNA-Seq using the newly developed tool, PopulASE. Labmate Steve Munger (The Jackson Laboratory; O-43) presented an application of the tool using expression data from the DO population, revealing that most variants influencing gene expression are local and act in cis in this population. Mark Thomas (Wellcome Trust Sanger Institute; O-54) relayed the importance of gene annotation for genome manipulation, with emphasis on analysis and evaluation of CRISPR resources. Goals of GENCODE include assistance with determining genome-editing strategies using the CRISPR-Cas9 system as well as guarding against off-target effects. Laurens Wilming (Wellcome Trust Sanger Institute; O-41) described efforts to annotate the Norway Brown rat reference genome through a community-based approach and underscored how gene annotation helps identify genome assembly issues.

Sarah Carpanini (University of Edinburgh; O-33) presented a clever approach to identify genes important in neurological processes. She described a multi-factorial bioinformatics scheme to sort through transcriptome datasets from the mammalian nervous system. The results of this in silico study revealed known as well as novel genes within neurological networks that may act as cell-type specific drug targets. 


\section{Verne Chapman Lecture: Bruce Beutler (O-20)}

The Verne Chapman Memorial Lecture was delivered by Dr. Bruce Beutler, Regental Professor and Director of the Center for Genetics of Host Defense at the University of Texas Southwestern Medical Center at Dallas. Dr. Beutler began with an overview of his scientific career and finished with a description of his laboratory's current focus, a largescale ENU mutagenesis screen.

Dr. Beutler described his early work on the innate immune response to bacterial infection, specifically the phenomenon of septic shock - the overwhelming immune response triggered by lipopolysaccharide (LPS, or endotoxin) present in the outer membrane of Gram-negative organisms. Several years of painstaking biochemistry work led to the isolation and identification of tumor necrosis factor alpha (TNF-alpha) as the critical host mediator of septic shock. Following this discovery, Dr. Beutler's group worked to develop a recombinant inhibitor by fusing a portion of the immunoglobulin heavy chain to the recognition moiety of the TNF-alpha receptor. That molecule was the basis for the design of the blockbuster rheumatoid arthritis drug, etanercept (Enbrel). Using TNFalpha production as an indicator of an intact response to LPS, Dr. Beutler's group used positional cloning to identify Tolllike receptor 4 (Tlr4) as the membrane-bound receptor for LPS. For his work in characterizing TLRs as the central components of innate and adaptive immunity, Dr. Beutler was awarded the Nobel Prize in Physiology or Medicine 2011.

In Dr. Beutler's rendition, the cloning of the LPS receptor led naturally to an interest in using forward genetics to probe the mammalian immune system. He narrated his laboratory's shift toward ENU mutagenesis beginning in the early 2000s and described in detail his current focus: an extremely ambitious effort toward a saturated, unbiased mutant screen in the mouse using ENU (www.mutagenetix.utsouthwestern.edu/). The breeding scheme introduces ENU-induced mutations through both the male and female germline, in order to increase the probability of observing mutations in the homozygous states and to recover mutations on the sex chromosomes. Pedigrees are screened for morphological and physiological abnormalities across all organ systems via a high-throughput phenotyping pipeline. Coarse genetic mapping of mutant phenotypes is performed by bulk segregation analysis using a sparse marker panel; only pedigrees with a single, high-confidence linkage peak are retained. Identification of a causal mutation is attempted by whole-exome sequencing.

This research program has generated 10,444 pedigrees comprising over 136,000 phenotyped offspring, leading to the identification of 275 phenotypes mapping to 170 genes. As expected, a much larger number of incidental mutations $(183,292)$ have accumulated in 20,690 genes. The process is limited only by the pace of breeding and phenotyping: either a casual variant is identified within days, or the pedigree is discontinued. Dr. Beutler described the utility of the screen for obtaining unbiased estimates of the effect spectrum of point mutations, in addition to the generation of genetically-characterized mutants.

\section{Keynote Lecture: Jeanne Lawrence (O-31)}

The keynote speaker was Dr. Jeanne Lawrence (University of Massachusetts Medical School) who shared her work on "translational epigenetics," which aims to use our understanding of epigenetics to treat chromosomal abnormalities. Dr. Lawrence's research focuses on the role of non-coding RNA in chromatin regulation.

Dr. Lawrence's group is investigating the use of XIST, the large non-coding RNA that induces X chromosome silencing in female mammalian cells, to treat chromosomal pathologies like trisomy. Her group has successfully developed human IPS cells which display XIST-mediated silencing of chromosome 21 , thus creating a "needed system to study initiation of human chromosome silencing." Dr. Lawrence's group demonstrated that chromosome 21 has the capacity to be silenced by the same RNA that evolved to regulate the X chromosome. By creating and studying a "disease in a dish," Dr. Lawrence's group has identified a new approach to advance Down's Syndrome research. Relevant mouse models, including the Ts65Dn and the TCL1 transgenic mouse lines, complement Dr. Lawrence's work in human IPS cells. Dr. Lawrence asserted that work in human IPS cells and mouse models demonstrates potential advances for trisomy treatments, noting that chromosome therapy is "uncertain but can now at least be considered." Dr. Lawrence noted challenges including delivery of the transgene, timing of delivery, and targeted insertion of XIST into affected chromosomes.

Dr. Lawrence's group is investigating a second area of fundamental biology around the potential roles of high-copy repetitive sequences. Of particular interest is Cot-1 repeat RNA. This abundant nuclear RNA is widespread, long-lived and remains bound to active chromosome territories after transcription arrest. Dr. Lawrence's group hypothesizes that different types of chromosomal RNAs, like Cot-1 repeat RNA, might regulate the epigenome. Dr. Lawrence encouraged research of the "repeat genome" because it may help explain how chromosomes are regulated and lead to new treatments for genetic disorders.

\section{Looking forward}

The outlook is bright for research using mammalian models to investigate diseases and complex traits, as well as fundamental questions in biology. The tools to manipulate 
genomes in precise fashion and recreate human variants in the mouse are unparalleled, as is the ability to measure a multitude of phenotypes with exquisite accuracy. The 29th IMGC will capitalize on these themes by bringing scientists together in Yokohama, Japan on November 8-11, 2015 (www.imgc2015.jp/). The IMGS invites you to join us along with our host, Dr. Piero Carninci, and the local organizing committee for this exciting and comprehensive meeting with emphasis on cutting-edge research in mammalian genetics and genomics.

\section{Special recognition}

The IMGS extends its deepest gratitude to Darla Miller for 27 years of hard work and selfless dedication to the IMGS organization, including the planning and execution of its meetings. To honor Ms. Miller, the IMGS established the "Darla Miller Distinguished Service Award" which will be given to a
Society member exemplifying outstanding service. Funds provided will help offset travel expenses to attend the IMGC and present a lecture that bridges science and service. Donations are accepted at www.gofundme.com/darlamilleraward.

Acknowledgments The IMGS extends its sincere gratitude to the organizing committee including Karen Svenson, Ron Korstanje, Erin McDevitt, and Nancy Place along with Darla Miller and Dasha Li Kappe for this outstanding meeting. The IMGS also thanks the Secretariat: President David Beier, Vice President Teresa Gunn, PastPresident David Threadgill, Sarah Carpanini, Piero Carninci, John Didion, Elena de la Casa Esperon, Jiri Forejt, Viive Howell, Darren Logan, Klaus Schughart, and Linda Siracusa. The IMGS is grateful to our meeting exhibitors and sponsors for their support: The Jackson Laboratory (Bar Harbor, ME), Dartmouse (Lebanon, NH), Geneseek a Neogen Company (Lansing, MI), Mouse Mutant Regional Resource Center supported by NIH (Chapel Hill, NC), Maverix Biomics (San Mateo, CA), and PLOS (San Francisco, CA). The IMGS thanks the publishers and companies referred to in Table 2 (American Association for Cancer Research, Cambridge Journals, Garland Science, genesis, Genetics Society of America, Genome Research, Genomics and Springer Verlag) for their generous donations of awards. 